\title{
Fluids and Containment Materials Compatibility Research
}

\author{
R. T. Coyle \\ T. M. Thomas \\ Paul Schissel
}

April 1985

Prepared for the

Annual Solar Thermal Research Conference Lakewood, Colorado

20-22 February 1985

Prepared under Task No. 5112.51

FTP No. 510

Solar Energy Research Institute

A Division of Midwest Research Institute

1617 Cole Boulevard

Golden, Colorado 80401

Prepared for the

U.S. Department of Energy

Contract No. DE-AC02-83CH10093 


\section{NOTICE}

This report was prepared as an account of work sponsored by the United States Government. Neither the United States nor the United States Department of Energy, nor any of their employees, nor any of their contractors, subcontractors, or their employees, makes any warranty, expressed or implied, or assumes any legal liability or responsibility for the accuracy, completeness or usefulness of any information, apparatus, product or process disclosed, or represents that its use would not infringe privately owned rights. 
FLUIDS AND CONTAINMENT MATERIALS COMPATIBILITY RESEARCH

R. T. Coyle, T. M. Thomas, Paul Schissel

Solar Energy Research Institute

Golden, CO 80401

\section{INTRODUCTION}

Objective

The objective of the research at SERI on fluids and containment materials compatibility is to ensure that materials and fluids for advanced high temperature solar thermal energy systems have adequate durability and suitable properties in the solar thermal environment. This environment includes diurnal cycling of the receiver, thermal transients due to clouds, and high intensities of solar radiation that can result in very rapid heating of receiver parts. The fluids required for advanced receivers with operating temperatures higher than $600^{\circ} \mathrm{C}$ are expected to give rise to additional issues of corrosion and erosion of the containment materials in contact with these fluids. The advanced fluids currently receiving the most attention are molten alkali carbonate salt and solid particles, both of which can be used in central receivers to absorb concentrated solar radiation.

In the short term, the compatibility research has been directed toward choosing materials and fluids for a pilot-scale test of the Direct Absorption Receiver, that is scheduled later this year at Georgia Tech Research Institute's Advanced Components Test Facility. We have chosen carbonate molten salt as the best heat transfer fluid for conducting these experiments after exploratory corrosion tests on materials in contact with sodium hydroxide, sodium-potassium-magnesium chloride, and sodium-potassium carbonate [1]. Molten eutectic Iithium-sodium-potassium carbonate was selected as the most suitable salt for the pilot scale test because of its low eutectic temperature $\left(397^{\circ} \mathrm{C}\right)$, and because it exhibited comparable materials compatibility to that observed with sodium-potassium carbonate at $900^{\circ} \mathrm{C}[2]$.

FY 1984 Objectives

The objectives of the fluids and containment compatibility research in FY 1984 were: 
- Evaluation of the corrosion of high purity alumina ceramics in eutectic lithium-sodium-potassium carbonate at $900^{\circ} \mathrm{C}$

- Evaluation of the corrosion of selected superalloys in eutectic Iithium-sodium-potassium carbonate at $900^{\circ} \mathrm{C}$

- Evaluation of the microstructure of the corrosion product for the alumina ceramics and the superalloys.

The emphasis in these corrosion studies was on Coors AD-998 aluminum oxide and on Inconel 600 since these were candidate high-temperature materials for constructing the pilot-scale Direct Absorption Receiver at Georgia Tech Research Institute. Studies were also done on the corrosion of sapphire (a single crystal form of aluminum oxide) as an aid to understanding the corrosion mechanism for alumina materials.

\section{FY 1984 Major Accomplishments}

The major accomplishments of this research in FY 1984 are listed below and are discussed in more detail in the results and discussion section.

- Low corrosion rates were shown for high purity alumina ceramics.

- A protective layer was shown to form on alumina.

- Metallography on Inconel 600 coupons indicated suitable lifetime for use in the pilot-scale experiment.

- Elevating the oxygen content in the molten salt was shown to reduce the corrosion of Inconel 600 .

\section{EXPERTMENTAL PROCEDURES}

\section{Corrosion Experiments}

An illustration of a crucible used to expose coupons of ceramic materials and metal alloys is shown in Figure 1. The crucible was made of nominally pure (99.8\%) aluminum oxide and contained molten salt to a height of about $13 \mathrm{~cm}$. All coupons were immersed in the molten salt and the molten-salt temperature was maintained at $900^{\circ} \mathrm{C}$. The top of the crucible was covered with a water-cooled plate; a thermocouple and gas purge tube were suspended in the crucible from this plate.

The coupons were 1.3 by $1.9 \mathrm{~cm}$ and were typically about $0.3 \mathrm{~cm}$ thick. Holes of about $0.4-\mathrm{cm}$ diameter were made in the coupons so we could mount them on pure (99.8\%) aluminum oxide sample holders using spacers of this ceramic to separate the coupons. The coupons were cleaned and weighed before testing. 


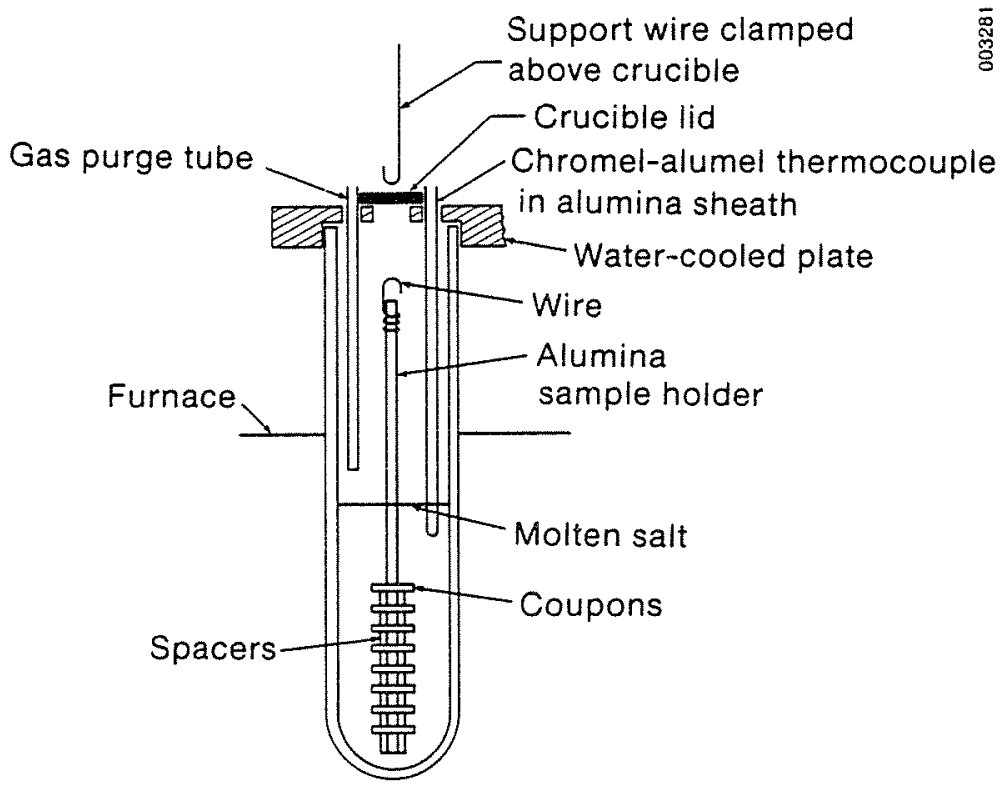

FIGURE 1. SCHEMATIC OF A CRUCIBLE FOR CONDUCTING MOLTEN-SALT CORROSION EXPERIMENTS.

\section{Weight Change Measurements}

Coupons, usually three, were exposed to molten salt over a specific time period and then removed for weighing. Coupon weights were measured after corrosion by first cleaning adherent salt from the coupon with distilled water, rinsing in acetone, and drying in an oven at $100^{\circ} \mathrm{C}$ for 1 hour. Weight changes were reported as milligrams per square centimeter of coupon surface area.

\section{Molten-Salt Chemistry}

We used a ternary eutectic lithium-sodium-potassium carbonate molten salt for these experiments $\left(43.5 \mathrm{~mol} \% \mathrm{Li}_{2} \mathrm{CO}_{3}, 31.5 \mathrm{~mol} \% \mathrm{Na}_{2} \mathrm{CO}_{3}\right.$, and 25 mol $\left.: \mathrm{K}_{2} \mathrm{CO}_{3}\right)$. The salt was prepared using reagent grade chemicals. The chemistry of the molten-salt system can be controlled by selecting the oxidation potential and basicity of the melt, respectively, by adjusting the level of oxygen and carbon dioxide in the system. The purge gas compositions used in these studies are given in Table 1. A quadrupole mass spectrometer was used to verify the composition of the gas in the crucibles. It was found that ain infiltrated the crucibles in varying degrees due to the design of the water-cooled plate (a new design has greatly reduced infiltration). The influence of this infiltration on the oxidation potential and basicity is discussed along with the corrosion results for each material. A more detailed description of the purge gas system can be found in Ref. 2. 
TABLE 1. GAS COMPOSITIONS.

\begin{tabular}{ccc}
\hline Purge Gas & Oxidation Potential & Basicity \\
\hline $80 \% \mathrm{Ar}, 20 \% \mathrm{CO}_{2}$ & low & low \\
$70 \% \mathrm{Ar}, 20 \% \mathrm{O}_{2}, 10 \% \mathrm{CO}_{2}$ & high & low \\
\hline
\end{tabular}

\section{RESULTS AND DISCUSSION}

\section{Corrosion Results on Aluminum Oxide}

Most of the effort on the corrosion of aluminum oxide was concentrated on the study of two materials, Coors AD-998, a $99.8 \%$ pure polycrystalline aluminum oxide, and the (110) surface of sapphire, a high purity, single crystalline form of aluminum oxide. The AD-998 was studied as a practical material that might be used in contact with molten salt; the sapphire, however, was studied primarily to aid in clarifying the nature of corrosion reactions between aluminum oxide and molten carbonate salt. AlI of the studies were done in the molten eutectic lithium-sodium-potassium carbonate at $900^{\circ} \mathrm{C}$.

The results of corrosion studies on sapphire at $900^{\circ} \mathrm{C}$ under conditions of low basicity and low oxidation potential are shown in Figure 2 . The purge gas was $80 \% \mathrm{Ar}$ and $20 \% \mathrm{CO}_{2}$, and the quadrupole analysis of the gas in the crucible showed $20 \% \mathrm{CO}_{2}$ and $0.3 \% \mathrm{O}_{2}$. The weight change of the coupon in milligrams per square centimeter of coupon surface area is presented for a number of exposure times up to 67 days. The error bar on each datum point represents one standard deviation above and below the mean for data from three coupons. There was no significant weight change between 9 and 67 days, and all of the coupons gained weight. This behavior is characteristic of the formation of a protective layer that slows further corrosion.

An SEM photograph showing the corrosion product on the (110) surface of a sapphire coupon is shown in Figure 3. This view was obtained by fracturing the coupon to expose a cross section of the coupon. The lower magnification photograph in A shows the fracture surface in the lower part of the photograph and the corrosion product in the upper part. In photograph $B$, at a higher magnification, the broken edge of the corrosion product is shown to be a series of densely packed columnar grains growing out of the (110) surface of the sapphire. 


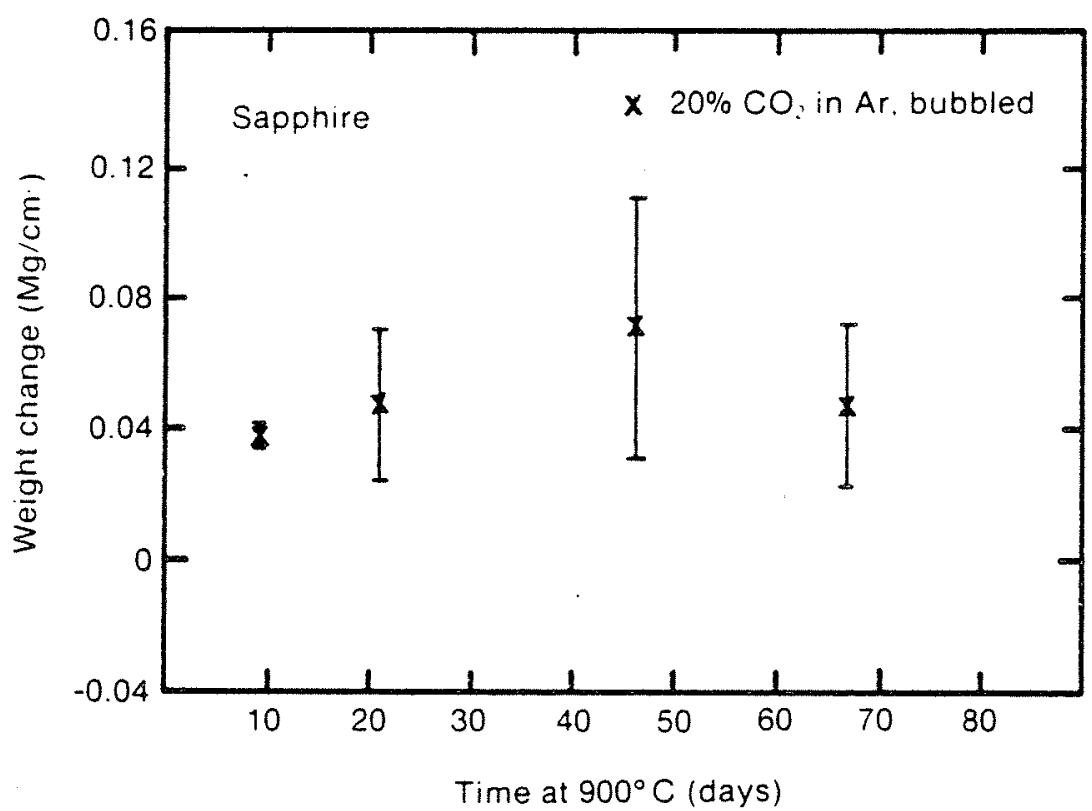

FIGURE 2. WEIGHT CHANGE RESULTS ON SAPPHIRE AFTER EXPOSURE TO EUTECTIC ( $\mathrm{Li}, \mathrm{Na}, \mathrm{K})_{2} \mathrm{CO}_{3}$ AT $900^{\circ} \mathrm{C}$.

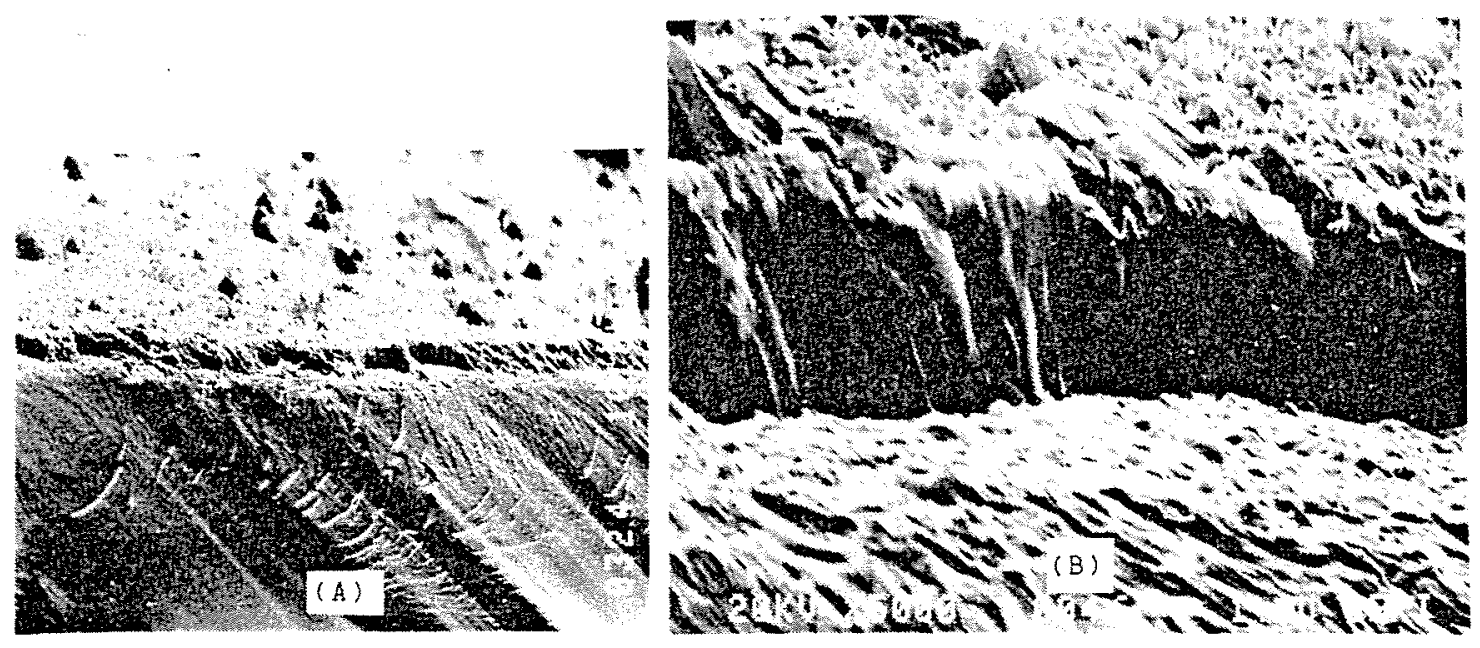

FIGURE 3. SAPPHIRE (110) SURFACE EXPOSED TO EUTECTIC ( $\mathrm{Li}, \mathrm{Na}, \mathrm{K})_{2} \mathrm{CO}_{3}$ AT $900^{\circ} \mathrm{C}$ FOR 46 DAYS WITH AN 80\% Ar-20\% $\mathrm{CO}_{2}$ ATMOSPHERE BUBBLED INTO THE SALT. (A) FRACTURE SURFACE WITH THE PROTECTIVE LAYER ACROSS THE TOP OF THE PHOTOGRAPH. (B) HIGHER MAGNIFICATION PHOTOGRAPH SHOWING THE THICKNESS OF THE PROTECTIVE LAYER AT THE TOP OF THE PHOTOGRAPH. 

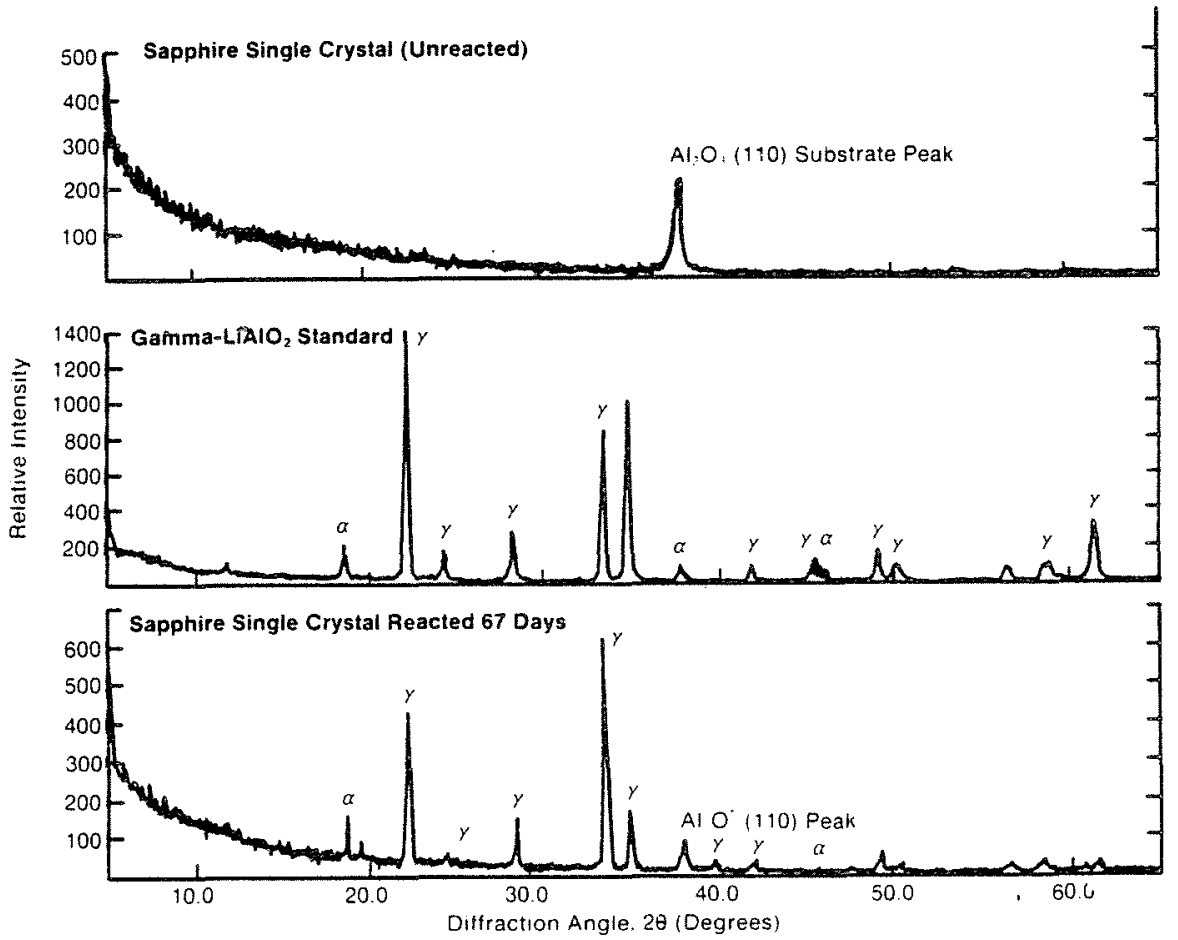

FIGURE 4. $X$-RAY DIFFRACTION PATTERNS FROM SAPPHIRE BEFORE AND AFTER EXPOSURE TO EUTECTIC $\left(\mathrm{Li}, \mathrm{Na}_{0} \mathrm{~K}\right), \mathrm{CO}_{3}$ AT $900^{\circ} \mathrm{C}$ FOR 67 DAYS AND FROM A GAMMA-LITTIIUM ALIMINATE STANDARD.

$X$-ray diffraction patterns of these materials (Chandra and Coyle [3]) are shown in Figure 4. The unreacted single crystal showed a (110) aluminum oxide peak and after reacting in the molten carbonate for 67 days a number of additional peaks appeared. These peaks matched well with the peaks for a gamma-lithium aluminate standard material. A few peaks of alpha-lithium aluminate also appeared in the standard material as well as in the corrosion product. The relative intensities of the gamma-lithium aluminate reaction product differ from those of the standard material. This is an indication of preferred orientation for growth of the aluminate from the (110) surface of the sapphire.

Figure 5 shows a mass balance for the growth of gamma-lithium aluminate after 67 days of exposure to the ternary eutectic carbonate at $900^{\circ} \mathrm{C}$. The starting weight of the sapphire coupon is shown on the right as the lower arrow to which another arrow is added. The $0.18 \mathrm{mg} / \mathrm{cm}^{2}$ magnitude of the added arrow is determined from the thickness of the gamma-lithium aluminate corrosion product, its theoretical density, and the estimate that there is about 10 volume $\%$ of voids in the corrosion product. The weight of lithium oxide in this amount of corrosion product is then the expected weight gain for the coupon provided no aluminum oxide is lost in the process of forming the product. However, the observed weight gain for this coupon, which is shown on the left, was $0.08 \mathrm{mg} / \mathrm{cm}^{2}$, substantially 


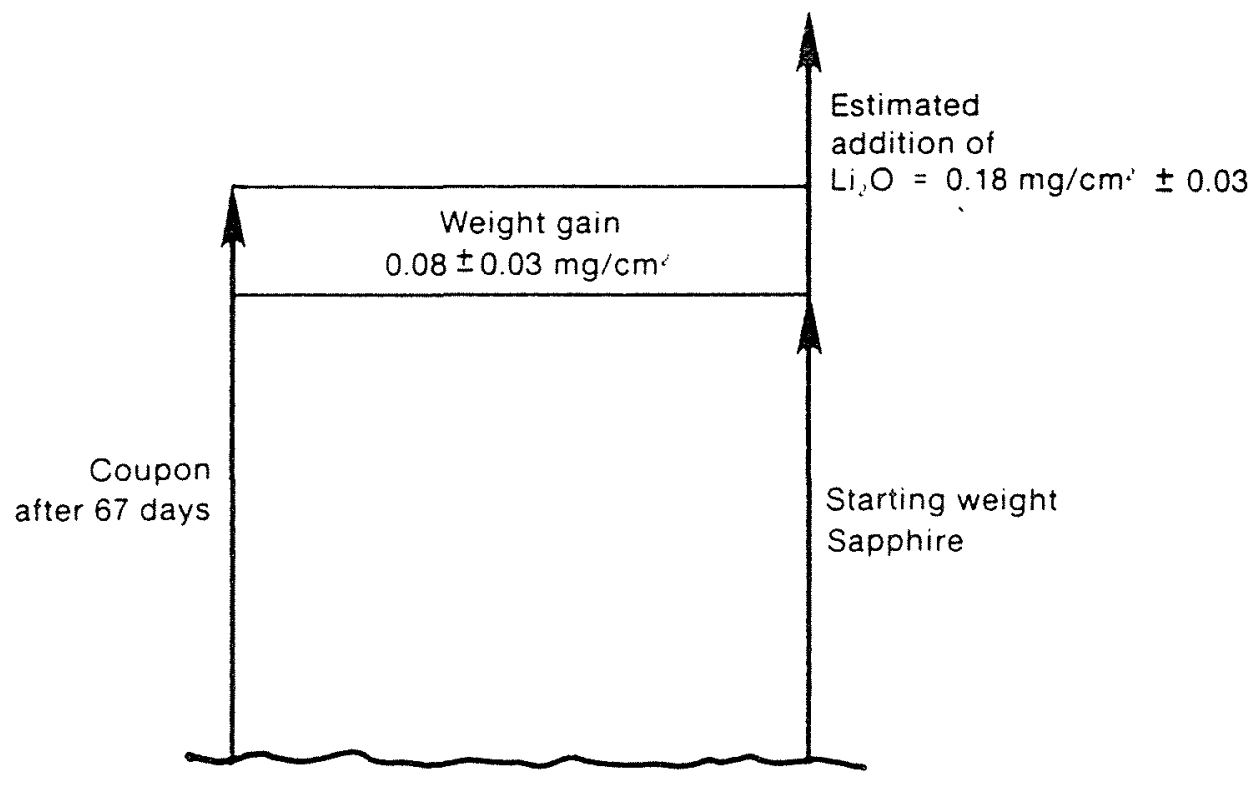

FIGURE 5. MASS BALANCE FOR THE GROWTH OF GAMMA-LIAlO 2 ON THE (110) PLANE OF SAPPHIRE IN $(\mathrm{Li}, \mathrm{Na}, \mathrm{K})_{2} \mathrm{CO}_{3}$ AT $900^{\circ} \mathrm{C}$ AFTER 67 DAYS.

less than expected from the mass balance on the right. Since there was no significant weight change between 9 and 67 days, this mass balance indicates that in the initial stages of the corrosion process some aluminum oxide was lost to the melt before the protective coating formed.

Similar results were seen in studies with the Coors AD-998 aluminum oxide material, where $x$-ray diffraction studies showed the formation of a gamma-lithium aluminate corrosion product that showed no preferred orientation as in the case with sapphire. This lack of preferred orientation is attributed to the random orientation of grains in the AD-998 polycrystalline material. The rate of weight change for this material indicated a corrosion rate of about $0.01 \mu \mathrm{m} /$ day. The gas above the salt contained $1 \% \mathrm{CO}_{2}$ and $18 \% \mathrm{O}_{2} \cdot$ The corrosion rate for the $A D-998$ was higher than for the sapphire, where little change in the weight of the coupons was seen between 9 and 67 days.

\section{Corrosion of Irrconel 600}

The corrosion on Inconel 600 in the ternary eutectic carbonate at $900^{\circ} \mathrm{C}$ was studied under conditions of low and high oxidation potential where the basicity was low in both cases. A metallographic section of Inconel 600 after 21 days of immersion under conditions of low oxidation potential is shown in Figure $6 \mathrm{~A}$. Extensive metal wastage 

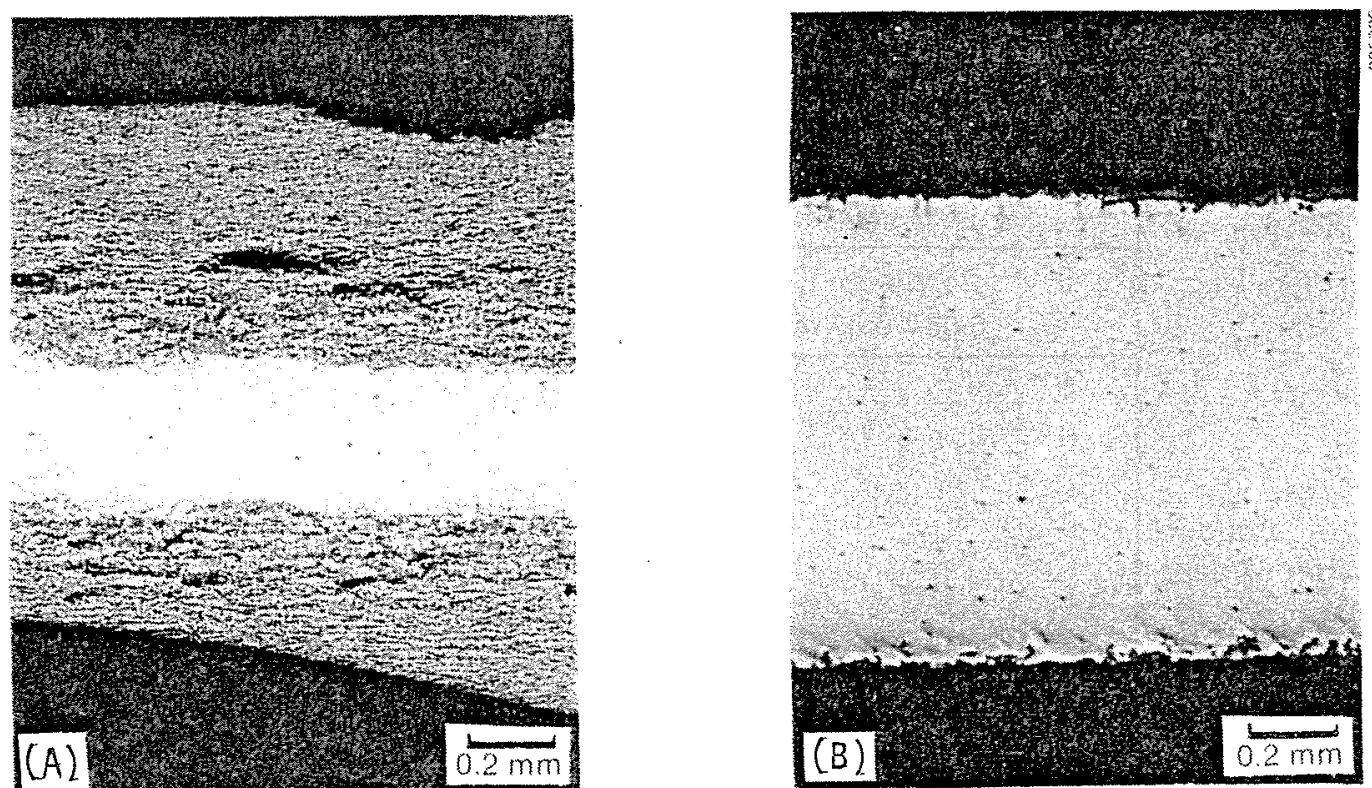

(A)
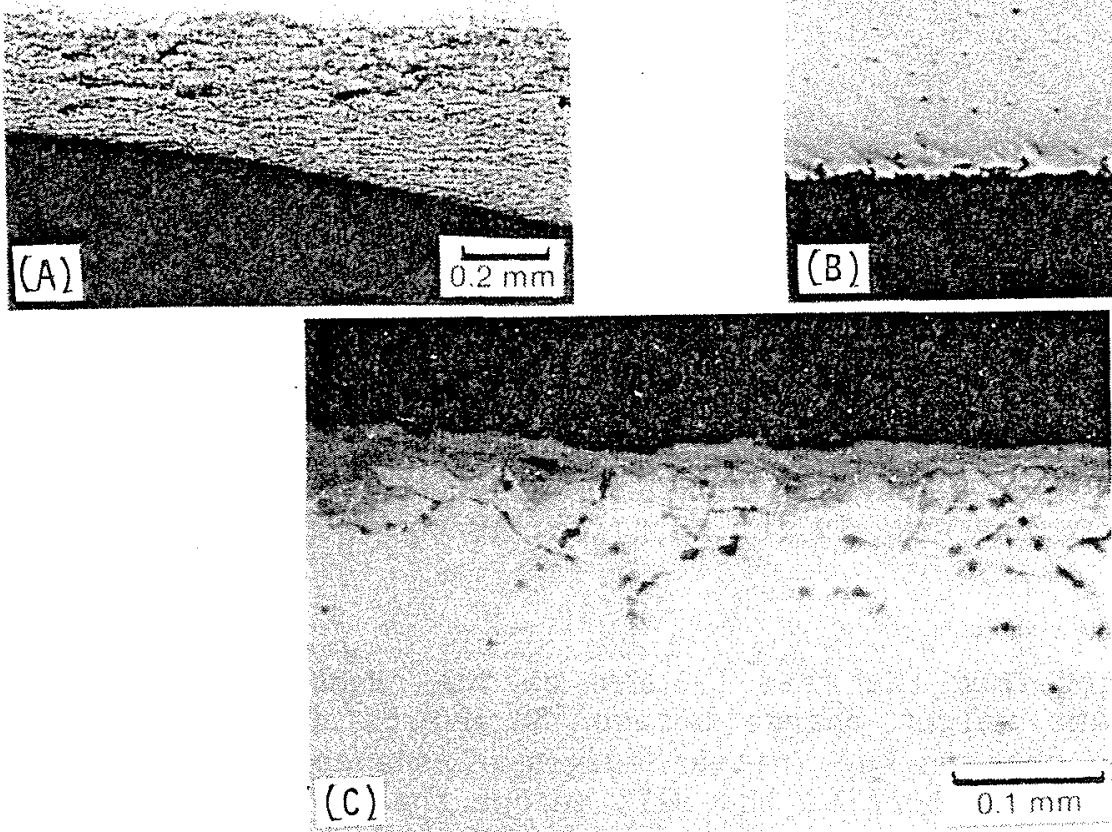

FIGURE 6. METALLOGRAPHIC SECTIONS OF INCONEL 600 EXPOSED TO EUTECTIC $(\mathrm{Li}, \mathrm{Na}, \mathrm{K})_{2} \mathrm{CO}_{3}$ AT $900^{\circ} \mathrm{C}$. (A) AFTER 21 DAYS BUBBLED WITH $80 \%$ $\mathrm{Ar}-20 \% \mathrm{CO}_{2} \cdot$ (B) AFTER 62 DAYS BUBBLED WITH $70 \%$ Ar-20\% $\mathrm{O}_{2}-10 \% \mathrm{CO}_{2}$. (C) HIGHER MAGNIFICATION OF (B).

has occurred and a porous corrosion product of the type reported by Coyle, Thomas, and Lai [4] is observed. The metallographic cross section for a coupon immersed for 62 days in the high oxidation potential salt is shown in Figure $6 \mathrm{~B}$ and $\mathrm{C}$. In this case, little metal wastage is observed, and as seen in $C$, the corrosion product on the surface of the coupon has a dense appearance.

The results of these metallographic examinations as well as others using different exposure times are given in Table 2. The low oxidation potential experiments resulted in greater metal loss than the high oxidation potential experiments. Additionally, there is not a clear increase in metal loss between 17 and 62 days for the latter case, which suggests that the dense corrosion product observed in Figure 6 for the coupons tested in the high oxidation potential may be 
protective and may lead to corrosion rates substantially less than the $3 \mathrm{\mu m} /$ day rate that can be calculated by linear extrapolation of the results at 62 days. Further, systematic studies of the influence of oxidation potential on the corrosion of Inconel 600 are needed to assess the degree of protection afforded by this dense corrosion product.

TABLE 2. CORROSION RESULTS FROM METALLOGRAPHY ON INCONEL 600.

\begin{tabular}{cccc}
$\begin{array}{c}\text { Immersion } \\
\text { Time }\end{array}$ & $\begin{array}{c}\text { Oxidation } \\
\text { Potential }\end{array}$ & Basicity & $\begin{array}{c}\text { Metal Loss } \\
\text { (mm/side) }\end{array}$ \\
\hline 21 & low & low & 0.56 \\
64 & low & low & 0.59 \\
17 & high & low & 0.12 \\
30 & high & low & 0.08 \\
62 & high & low & 0.17 \\
\hline
\end{tabular}

The low oxidation potential experiments were done using an $80 \% \mathrm{Ar}$ and $20 \% \mathrm{CO}_{2}$ purge gas. Quadrupole analysis of the gas above the molten salt showed $16 \% \mathrm{CO}_{2}$ and $6 \% \mathrm{O}_{2}$. To simulate ambient potential, the high oxidation potential experiments were conducted using a purge gas that contained.70\% $\mathrm{Ar}, 20 \% \mathrm{O}_{2}$, and $10 \% \mathrm{CO}_{2}$, and the quadrupole analysis showed $22 \% \quad \mathrm{O}_{2}$ and $11 \% \mathrm{CO}_{2}$. The major difference between these two experiments was that the oxygen-containing purge gas was bubbled into the salt in the high oxidation potential experiment and non-oxygen-containing gas was bubbled into the molten salt for the low oxidation potential experiment; there was also less oxygen in the gas above the salt for the latter condition.

\section{CONCLUSIOHS}

The conclusions from these corrosion studies are:

- Low corrosion rates were observed for Coors AD-998 alumina; the rate was $0.01 \mu \mathrm{m} /$ day for this ceramic and much lower for the (110) surface of sapphire.

- Inconel 600 shows promise of corrosion rates of less than $3 \mu \mathrm{m} / \mathrm{day}$.

- Both high alumina ceramics and the Inconel 600 were observed to form a dense corrosion product that diminished the rate of subsequent corrosion. 


\section{FUTURE PLAHS}

The presence of the layer of corrosion product that impedes further corrosion of the aluminum oxide ceramics and the Inconel 600 suggests that disruption of that layer could lead to more rapid corrosion. One process that could lead to disruption of the protective corrosion product is thermal cycling. The direct absorption receiver is expected to cycle between $900^{\circ} \mathrm{C}$ and some lower temperature on a diurnal schedule. In FY 1985 we plan to conduct thermal cycling tests in the molten salt between $500^{\circ}$ and $900^{\circ} \mathrm{C}$ to evaluate the alumina and the Inconel 600 for susceptibility to enhanced corrosion under cycling.

More detailed studies such as evaluation of the influence of oxidation potential and basicity on the corrosion of alloys and ceramics will be required to evaluate the potential of these materials for long-term durability.

\section{MCKNOWLEDGMENTS}

We acknowledge the contributions that were made to this work by $Y$. Shinton and D. Burrows.

\section{REFERENCES}

1. Coyle, R. T., et al., Exploratory Corrosion Tests on Materials and Fluids for Advanced High-Temperature Molten Salt Storage, Solar Energy Research Institute, Golden, CO, October, 1984. (SERI/TR255-2199)

2. Coyle, R. T., T. M. Thomas, and Paul Schissel, The Corrosion of Materials in Molten Alkali Carbonate Salt at $900^{\circ} \mathrm{C}$, Solar Energy Research Institute, Golden, CO, Draft. (SERI/TR-255-2553)

3. Chandra, D. and R. T. Coyle, Characterization of Passivating Corrosion Layers Formed on High Temperature Ceramic Materials by Molten Carbonate Salt Reaction, Solar Energy Research Institute, Golden, CO, Draft.

4. Coyle, R. T., T. M. Thomas, and G. Y. Lai, "Exploratory Corrosion Tests on Alloys in Molten Salts at $900^{\circ} \mathrm{C}$," in the Proc. of High Temperature Corrosion in Energy Systems, an International Symposium, Detroit, MI, Sept. 17-19, 1984. 